\title{
A case report of roflumilast in an elderly COPD patient: improving exercise capacity to improve quality of life
}

\author{
Daniela Parola ${ }^{1}$, Ambra Castagnacci ${ }^{*}$, Sara Salvati ${ }^{1}$
}

ABSTRACT: A case report of roflumilast in an elderly COPD patient: improving exercise capacity to improve quality of life. D. Parola, A. Castagnacci, S. Salvati.

This report describes a case of a 73-year-old man with chronic obstructive pulmonary disease (COPD) grade D. His walking abilities were seriously compromised due to chronic respiratory failure and arthrosis causing chronic joint pain. The patient frequently experienced exacerbation events, requiring hospitalization. After roflumilast therapy was started, the patient gradually regained the ability to move autonomously, and $\mathrm{FEV}_{1}$ values gradually increased too. This led to a general improvement of the patient's quality of life $(\mathrm{QoL})$, underlining how important movement abilities are in determining a patient's QoL and how roflumilast therapy is effective in improving exercise capacity in a patient with COPD.

Monaldi Arch Chest Dis 2013; 79: 3-4, Suppl., 35-40.

Keywords: Roflumilast, COPD, Exercise capacity, Case report.

1 Rehabilitation of Respiratory Failure Unit, "Umberto I" Polyclinic, Department of Cardiovascular, Respiratory, Nephrology, Anesthesiology and Geriatric Sciences, "La Sapienza" University of Rome, Italy.

Correspondence: Dr. Daniela Parola, MD, UOS di Riabilitazione dell'Insufficienza Respiratoria, Dipartimento di Scienze Cardiovascolari, Respiratorie, Nefrologiche, Anestesiologiche e Geriatriche, Policlinico Umberto I, Università di Roma “La Sapienza”, Viale del Policlinico 155,00161 Roma, Italy; e-mail: daniela.parola@uniroma1.it

\section{Case Report}

Here, we report a case of a 73-year-old man who was a former heavy smoker (30 pack-years), with chronic obstructive pulmonary disease (COPD) grade D according to GOLD guidelines [1]. The patient dis- played a marked deterioration of his general physical conditions, and suffered from chronic respiratory failure, requiring long acting oxygen therapy (1,5 L/min, 24h/day). $\mathrm{He}$ also showed chronic joint pain due to arthrosis, which was treated with chronic analgesic therapy. The baseline post-bron-

This work originated from the Policlinico Umberto I, Università di Roma "La Sapienza", Viale del Policlinico 155, 00161 Roma, and has been supported by a grant from Takeda Italia SpA.

* This author received a consultancy fee from Takeda Italia SpA for clinical data collection.

Editorial assistance was provided by Daria Bottai, PhD and Selene Mogavero, PhD (Primula Multimedia SrL) and was sponsored by Takeda Italia SpA. 
chodilator (BD) forced expiratory volume in the first second $\left(\mathrm{FEV}_{1}\right)$ value was $38 \%$. The 6-minute walk test (6MWT) was not concluded, due to his severe ventilatory syndrome and respiratory failure. Indeed, one minute after starting the test, the subject displayed asthenia and dyspnea (Borg scale dyspnea index - BSDI - >8). At this time the patient had a body mass index (BMI) of 28.3, COPD assessment test (CAT) score of 23, quality of life (QoL) score, assessed by the EuroQoL-5D questionnaire, of 0.231, BODE (BMI, obstruction, dyspnea, exercise capacity health index) of 8 .

In December 2011, due to frequent exacerbation events, which often required hospitalization, the patient was treated with roflumilast in association with long-acting $\beta 2$-agonists and inhaled corticosteroids at the maximal dose. The follow-up controls were performed after 3, 9 and 12 months. The ob- served $\mathrm{FEV}_{1}$ values were $41 \%, 48 \%$ and $52 \%$, at the respective time points (figure 1). No exacerbation events occurred, and a general improvement in the patient's condition was observed. After a 12-month treatment period, the patient successfully performed the 6MWT: the distance covered was 200 meters, and dyspnea, assessed by a BSDI of 5, had improved. Although the patient still suffered from respiratory failure and required oxygen therapy $(1.5 \mathrm{~L} / \mathrm{min}$, 24h/day), the patient's QoL significantly improved, as revealed by a CAT score of 17 and EuroQoL-5D score of 0.587. Patient BMI was 27.75 , and BODE was 4 .

The patient regained the ability to move autonomously. Of note, no side effects were detected over the 1-year treatment period with roflumilast. A reduction in BMI was observed, from 28.3 at the start of treatment to 27.8 after 1 year.

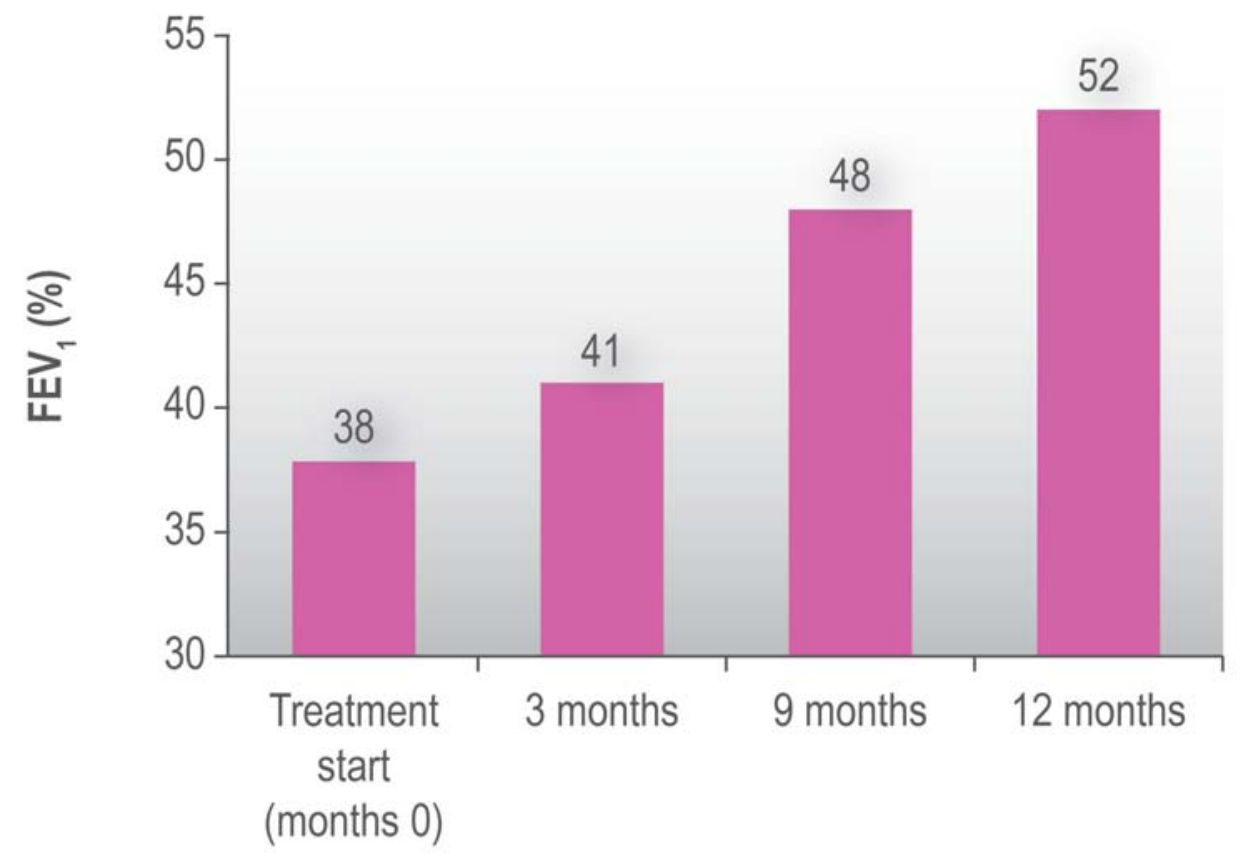

Fig. 1 - Changes observed in patient's $\mathrm{FEV}_{1}$ values, after he started therapy with roflumilast in association with long-acting $\beta 2$-agonists and inhaled corticosteroids at the maximal dose. $\mathrm{FEV}_{1}$, forced expiratory volume in the first second. 


\section{Discussion}

Several clinical trials conducted on large groups of patients demonstrated the efficacy and safety of roflumilast in the treatment of severe COPD associated with chronic bronchitis and frequent exacerbation events $[2,3]$. Roflumilast was observed as being extremely effective in reducing the number of moderate and severe exacerbations in patients who displayed 2 or more exacerbation events per year in the absence of therapeutic treatment [2-4]. It has been proposed that these patients can be referred to as a specific phenotype, the "frequent exacerbation phenotype" [5]. The aim of the roflumilastbased treatment, in association with BD therapy, described in the present report was to reduce the frequency of exacerbation events. In agreement with previous studies, the results described in the present report emphasize the beneficial effect of roflumilast in reducing exacerbation events, with consequent improvement of patient's QoL, favorable disease progression as well as a reduction in economical costs of COPD [6]. In addition, the progressive increase of $\mathrm{FEV}_{1}$ values observed over a 1 -year period further confirmed that roflumilast can improve lung function, although its activity does not directly induce dilatation of the bronchus [7]. It has been proposed that preand post- out-patient pulmonary rehabilitation (OPR) 12 minutes walking distance is one of the most significant predictors of survival in patients affected by advanced chronic lung failure. Patients with low timed walking distance have been shown to have increased mortality both from respiratory and non-respiratory causes [8]. Other predictive variables related to increased mortality are: low $\mathrm{FEV}_{1}$ values, reduced partial pressure of oxygen in arterial blood $\left(\mathrm{PaO}_{2}\right)$ and elevated $\mathrm{PaCO}_{2}$ (partial pressure of carbon dioxide in arterial blood), low BMI and increased dyspnea [8]. Several studies have analyzed the relationship of these variables and the reduced exercise ability in COPD patients [9-12]. Data obtained in one of these studies suggested that $\mathrm{FEV}_{1}$ and forced vital capacity values could not be considered as optimal predictive indicators of tolerance of physical exercise [9]. In contrast, results obtained in other studies demonstrated a good correlation between reduced inspiratory capacity, dynamic hyperinflation index, and reduced tolerance to physical exercise.

At present, experimental or clinical evidence supporting a positive effect of roflumilast on reduction of hyperinflation, with consequent increasing of inspiratory capacity in resting condition or during physical exercise, have yet not been provided. Conflicting results were reported in a recent study, in which the physiological effects of roflumilast at rest and during exercise in COPD patients were evaluated. In that study, no significant improvement of exercise ability was detected, although a small increase in oxygen saturation levels and ventilation during physical exercise were observed [13].

Data described in the present report, namely the improvement of the patient's exercise ability after treatment with roflumilast (evaluated by the 6MWT and reduction of the BSDI), represent the first clinical evidence of a positive correlation between roflumilast therapy and increased tolerance to physical exercise. However, it should be mentioned that additional assays testing the tolerance to physical exercise were not performed.

The poor QoL is a typical feature in patients with severe COPD and frequent exacerbations [1]. In the case reported here, a marked improvement in patient's QoL was observed, regarding psychophysical conditions, mood, and participation to family life.

The recurrence of side effects after roflumilast therapy was reported in several clinical studies, with a frequency of 3-5\% [14]. In contrast, no side effects involving the gas- 
trointestinal tract nor the central nervous system were observed in this clinical case. It is noteworthy that only a reduction in BMI was observed. It is possible that the loss of weight observed is related to the re-gaining of exercise capacity and the resumption of physical activity.

In conclusion, observations described in this report indicate that roflumilast-based therapy results in a decrease of the number of exacerbation events and significant improvement of ventilatory parameters with consequent increase in exercise capacity and tolerance to physical effort. Collectively, these data (airflow obstruction, entity of dyspnea, exercise capacity) are summarized in the BODE index, which is obtained by the combination of BMI and $\mathrm{FEV}_{1}$ values, responses to the questionnaire proposed by the Medical Research Council, and results of the 6MWT [15]. The BODE index thus represents an extremely valuable prognostic parameter in patients with COPD [15]. In the clinical case we have described, a significant reduction of the BODE index was observed, with consequent improvement of the prognosis quod vitam.

\section{Riassunto}

Si riporta qui il caso di un uomo di 73 anni, affetto da broncopneumopatia cronica ostruttiva (BPCO) di grado D. La sua capacità di camminare era seriamente compromessa a causa di una insufficienza respiratoria cronica e di un'artrite causa di dolori articolari cronici. Il paziente ha subito frequenti riacutizzazioni che richiedevano ospedalizzazione. Dopo aver iniziato la terapia con roflumilast, il paziente ha gradualmente recuperato la capacità di muoversi autonomamente, ad anche $i$ valori di FEV ${ }_{1}$ sono andati aumentando gradualmente. Questo ha portato ad un miglioramento generale della qualità di vita (QoL) del paziente, sottolineando quanto sia importante la capacità di movimento nel determinare la QoL del paziente e come la terapia con roflumilast sia efficace nel migliorare le capacità motorie in un paziente affetto da BPCO.

Parole chiave: Roflumilast, BPCO, Capacità motorie, Caso clinico.

\section{References}

1. Global Initiative for Chronic Obstructive Lung Disease (GOLD). Global Strategy for the Diagnosis, Management and Prevention of COPD. 2013. Available at www.goldcopd.org.

2. Calverley PMA, Rabe KF, Goehring U-M, et al Roflumilast in symptomatic chronic obstructive pulmonary disease: two randomised clinical trials. Lancet 2009; 374 (9691): 685-694.

3. Fabbri LM, Calverley PMA, Izquierdo-Alonso $\mathrm{JL}$, et al. Roflumilast in moderate-to-severe chronic obstructive pulmonary disease treated with longacting bronchodilators: two randomised clinical trials. Lancet 2009; 374 (9691): 695-703.

4. Wedzicha JA, Rabe KF, Martinez FJ, et al. Efficacy of roflumilast in the COPD frequent exacerbator phenotype. Chest 2013; 143: 1302-1311.

5. Hurst JR, Vestbo J, Anzueto A, et al. Susceptibility to exacerbation in chronic obstructive pulmonary disease. N Engl J Med 2010; 363: 11281138.

6. Wedzicha JA, Seemungal TAR. COPD exacerbations: defining their cause and prevention. Lancet 2007; 370 (9589): 786-796.

7. Grootendorst DC, Gauw SA, Baan R, et al. Does a single dose of the phosphodiesterase 4 inhibitor, cilomilast (15 mg), induce bronchodilation in patients with chronic obstructive pulmonary disease? Pulm Pharmacol Ther 2003; 16: 115-120.

8. Gerardi DA, Lovett L, Benoit-Connors ML, et $a l$. Variables related to increased mortality following out-patient pulmonary rehabilitation. Eur Respir J 1996; 9: 431-435.

9. Murariu C, Ghezzo H, Milic-Emili J, Gautier H Exercise limitation in obstructive lung disease. Chest 1998; 114: 965-968.

10. Milic-Emili J. Inspiratory capacity and exercise tolerance in chronic obstructive pulmonary disease. Can Respir J 2000; 7: 282-285.

11. Celli B, ZuWallack R, Wang S, Kesten S. Improvement in resting inspiratory capacity and 
hyperinflation with tiotropium in COPD patients with increased static lung volumes. Chest 2003; 124: 1743-1748.

12. Nanas S, Nanas J, Papazachou O, et al. Resting lung function and hemodynamic parameters as predictors of exercise capacity in patients with chronic heart failure. Chest 2003; 123: 1386-1393.

13. O'Donnell DE, Bredenbröker D, Brose M, Webb KA. Physiological effects of roflumilast at rest and during exercise in COPD. Eur Respir J 2012; 39: 1104-1112.

14. European Medicine Agency. Daxas, Summary of Product Characteristics. 2013.

15. Celli BR, Cote CG, Marin JM, et al. The bodymass index, airflow obstruction, dyspnea, and exercise capacity index in chronic obstructive pulmonary disease. $N$ Engl J Med 2004; 350: 1005-1012. 


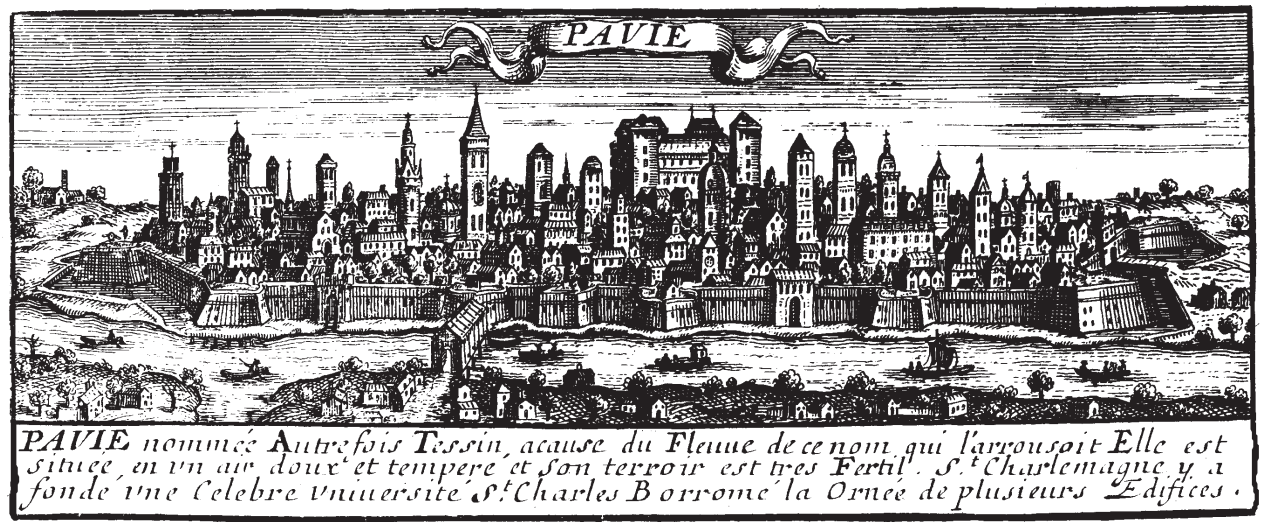

